\title{
Nested Diagnostic Context
}

National Cancer Institute

\section{Source}

National Cancer Institute. Nested Diagnostic Context. NCI Thesaurus. Code C62616.

An instrument to distinguish interleaved log output from different sources. 